\title{
Teaching new dogs old tricks
} Miranda Robertson

It is much too early to discuss even preliminary results from our experiment with re-review opt-out [1], and will be for some time, although we may report on interesting anomalies if there are enough of them. But in the meantime, Virginia Walbot, in this issue of Journal of Biology [2], has a practical suggestion on the complaint that stimulated us to embark on the experiment: namely, referees who seem to consider it their responsibility to prevent the publication of the papers they review; or at least to ensure that they cannot be published rapidly.

Walbot's Comment has been so highly accessed since it was posted that it is unlikely that anyone reading this editorial has not already read it. But I should like to make one point. It is very easy, and no doubt cathartic, to complain about what is wrong with prevailing refereeing practices. Walbot has tackled the more difficult question of what might be done to change it, with a carefully formulated protocol for accelerating the acquisition by young scientists of the maturity of perspective and judgement to distinguish clearly between reasonable papers that would, or might, benefit from revision, and those that really should not be published as they stand. If this can be achieved, it is not only authors but editors who will owe her a debt of gratitude.

We have another didactic contribution in this issue of the journal. This month we publish the third in our Questionand-Answer series. These articles are intended to be heterogeneous, some addressing topical issues with what amounts almost to a series of FAQs; some allowing a semi-random walk through points of interest on a current focus of attention; and some strictly instructive. These categories are nonexclusive, and our first Q\&A, from James Ferrell on systems biology [3], is partly in the first and partly in the third category. Our second, from Paul Harvey on Darwin [4], falls into the second. Our third, published in this issue [5], is instructive.

The objective of the instructive articles is twofold. Some are intended to explain to nonspecialists areas of research that are of current interest or importance but whose language or technology, or both, may not be easily understood by readers remote from the field. Others may be intended to clarify terms or concepts that may have a long history in the course of which they have somehow failed to acquire a generally understood meaning - or new coinages for which a consensus definition has not yet emerged, or perhaps perverse usages that are a source of confusion. An example of such a term would be epigenetics, recently discussed not by us in Q\&A format, but in a free-form piece in Current Biology by Mark Ptashne [6]. In a forthcoming issue, we shall be tackling epistasis - the term and the phenomenon.

In this issue, Trudy Mackay offers an explanation, in Q\&A format, of the genetic analysis of quantitative traits still one of the high-hanging fruit of genetics, because - as she explains quantitative traits depend on very small effects of a very large number of genes, each quite likely to be modified by the environment, and thus defying Mendelian analysis. (In fact, it turns out that the fruit are hanging even further from reach than was initially supposed though not beyond the ingenuity of modern genetic technology.) We invited the article because we believe many readers may be interested in what is important about these traits and how they can be analyzed despite the difficulties.

Readers must judge whether the question-and-answer format helps.

Miranda Robertson, Editor

editorial@jbiol.com

\section{References}

I. Robertson M: What are journals for? J Biol 2009, 8:I.

2. Walbot V: Are we training pit bulls to review our manuscripts? J Biol 2009, 8:24.

3. Ferrell JE Jr: Q\&A: Systems Biology. J Biol 2009, 8:2.

4. Harvey P: Q\&A: What did Charles Darwin prove? J Biol 2009, 8: I I.

5. Mackay TFC: Q\&A: Genetic analysis of quantitative traits. J Biol 2009, 8:23.

6. Ptashne M: On the use of the word 'epigenetic'. Curr Biol 2007, I7:R233-6.

Published: 17 April 2009

Journal of Biology 2009, 8:22

(doi: I0.1 I86/jbioll 36)

The electronic version of this article is the complete one and can be found online at http://jbiol.com/content/8/3/22

(c) 2009 BioMed Central Ltd 